\title{
Charitable Sporting Events as a Context for Building Adolescent Generosity: Examining the Role of Religiousness and Spirituality
}

\author{
Nathaniel A. Fernandez *, Sarah A. Schnitker and Benjamin J. Houltberg \\ School of Psychology, Fuller Theological Seminary, 135 N Oakland Ave, Pasadena, CA 91182, USA; \\ sschnitker@fuller.edu (S.A.S.); bhoultberg@fuller.edu (B.J.H.) \\ * Correspondence: nathanielfernandez@fuller.edu; Tel.: +1-626-765-5479 \\ Academic Editor: Patricia Snell Herzog \\ Received: 23 January 2016; Accepted: 15 March 2016; Published: 21 March 2016
}

\begin{abstract}
Previous research demonstrates an association between religiousness, spirituality, and generosity in adolescents, but few studies have tested the mechanisms by which religion might facilitate the development of generosity in real-world contexts. In this paper, a theoretical model is presented describing the potential mechanisms by which engagement in transformational contexts (i.e., participating in charity marathon training) may lead to the development of generosity in adolescents. Participation in charity sporting events is theorized to increase generosity through both higher-order mechanisms, such as sanctification and the development of transcendent identity, and lower-order mechanisms, such as increased entitativity, positive emotions, and dissonance reduction. An empirical strategy for testing the model is presented; suggested methods for inquiry are longitudinal mixed method designs incorporating observations, questionnaires, and qualitative interviewing. Additionally, a case study of ongoing research on adolescents running with Team World Vision is described as an application of the model to an actual research context.
\end{abstract}

Keywords: generosity; religion; spirituality; adolescents; sport

\section{Introduction}

The effects of religiousness on the development of generosity is a topic of great interest to scientists and practitioners alike, but methodological and research design constraints of previous studies limit conclusions that can be made from the extant literature. There is ample evidence that religiosity is a factor in predicting at least certain kinds of generosity in adults (i.e., in-group generosity [1]), but this evidence is somewhat controversial, with small effects found in meta-analyses [2]. Moreover, fewer empirical studies have looked at spirituality and generosity in children and adolescents (compared to adults), and most studies with children and adolescents have established correlational associations rather than testing causal mechanisms of change. However, information on how the ways that adolescents make meaning of their spiritual and religious convictions in real-world contexts affect the development of generosity is an important line of research. This is especially true as changing social norms and ever-developing technology and social media continue to shape upcoming generations in new ways [3].

Generosity in adolescents has been defined as the "'work' that persons engage and through which they expend themselves in order to increase the good of the other" ([4], p. 1). We conceptualize generosity as encompassing the giving of both more objective resources (e.g., money, labor, time), as well as more subjective resources (e.g., attention, emotions, energy), but we distinguish generosity from other attributes such as empathy or compassion, which more primarily involve emotional reactions to others and do not necessitate a social exchange in conceptual definitions (though generous giving is a common outcome) [5]. 
Several studies have examined associations between religiousness/spirituality and generosity in adolescent populations [6-8]. However, many of these studies tend to focus more generally on connections between religiosity and generosity without testing the possible mechanisms for these effects. For instance, James and Fine found that adolescent participants coded as having a more coherent spirituality or sense of purpose (as opposed to an ambiguous spirituality) scored higher on measures of all six "Cs" of positive youth development (i.e., Competence, Confidence, Character, Connection, Caring/Compassion, and Contribution), with higher scores on the Contribution factor indicating higher levels of generosity [9]. Similarly, Spiewak and Sherrod found that generosity was correlated with religious beliefs, spiritual transcendence, and religious practices in a cross-sectional sample of adolescents and emerging adults [10], and Bussing, Kerksieck, Günther, and Baumann found that spirituality and religiousness were correlated with generative altruism in adolescents and emerging adults [11]. Although these are important contributions to the literature in establishing empirical relations between religion, spirituality, and generosity, they do not address causal processes or the directionality of effects.

Additionally, much of the research on this topic that does address causation and mechanisms focuses on laboratory tasks that assess generosity and religiosity outside their ecological contexts [12]. These studies provide important information about causal processes, but there is a need for more studies aimed at real-world applicability, especially to those who are interested in considering how to foster religiosity and generosity. This is especially true for adolescent populations because researchers have demonstrated that the religiousness and spirituality of adolescents is often highly interpersonal and affected by social and cultural context [13]. In order to develop insight into how religious and spiritual variables affect the development of generosity in adolescents, it is important to study the phenomena as they are occurring in the real world.

One possible avenue for research to explore is the effects of major generosity-building contexts that young people are engaged in, such as charity sporting events. A broad array of charity walks, tournaments, races, fun runs, and the like are put on every year by all kinds of organizations. A Google search for "charity sporting events" yields millions of hits. These kinds of programs are also popular with adolescents because the events require more time engagement than direct monetary engagement on the part of the participant. Feldman demonstrated that donations of time and money are interchangeable, and adolescents are more likely to have excess time than money available for charity [14]. From a positive youth development perspective [15], adolescents' participation in these sporting events are likely major developmental assets in terms of their ability to promote positive developmental outcomes. However, how do these potential assets function to increase both religiosity and generosity? Moreover, how do events that are tied to religious organizations or activate spirituality have, perhaps, a greater potential to build adolescent generosity?

To address these questions, our research team has constructed a theoretical model to understand the various mechanisms by which participation sporting events affect spirituality and generosity, and we are in the process of conducting a study that examines adolescent religiousness, generosity, and key mediating/moderating variables in a real-world context. Although results of the study will not be presented in this paper, we will use our study design as a case study to illustrate the processes of change in our theoretical model and to depict the type of study design for which we are advocating. The study follows a group of adolescents over the course of their participation in a charity marathon or half marathon with a religious nonprofit organization dedicated to the cause of providing clean water initiatives to the developing world. Using a mixed method approach, we are gathering longitudinal questionnaire data and in-depth qualitative interviews from participants, as well as objective outcomes, such as race performance and money raised by participants. Participants are tracked from the point at which they sign up for training through two months post-race. Our study is an example of a design that can address previously stated gaps in the literature by gathering specific information to test mechanisms of change across time and by studying religiosity and generosity in an ecologically valid way within the actual experiences of adolescents in the real world rather than in laboratory conditions. 
As this research is ongoing, we present here our proposed theoretical model and rationale, with a focus on the predisposing factors that might lead adolescents to participate in these kinds of events and the mechanisms that might produce subsequent increases in religiosity and generosity. Our hope is that this theoretical model will guide other teams seeking to examine faith and generosity in youth. We present our model (Figure 1) piece by piece, explaining the rationale for proposed pathways, starting with factors predisposing adolescents to participate in charity marathon events and moving on to those processes that may be activated by participation.

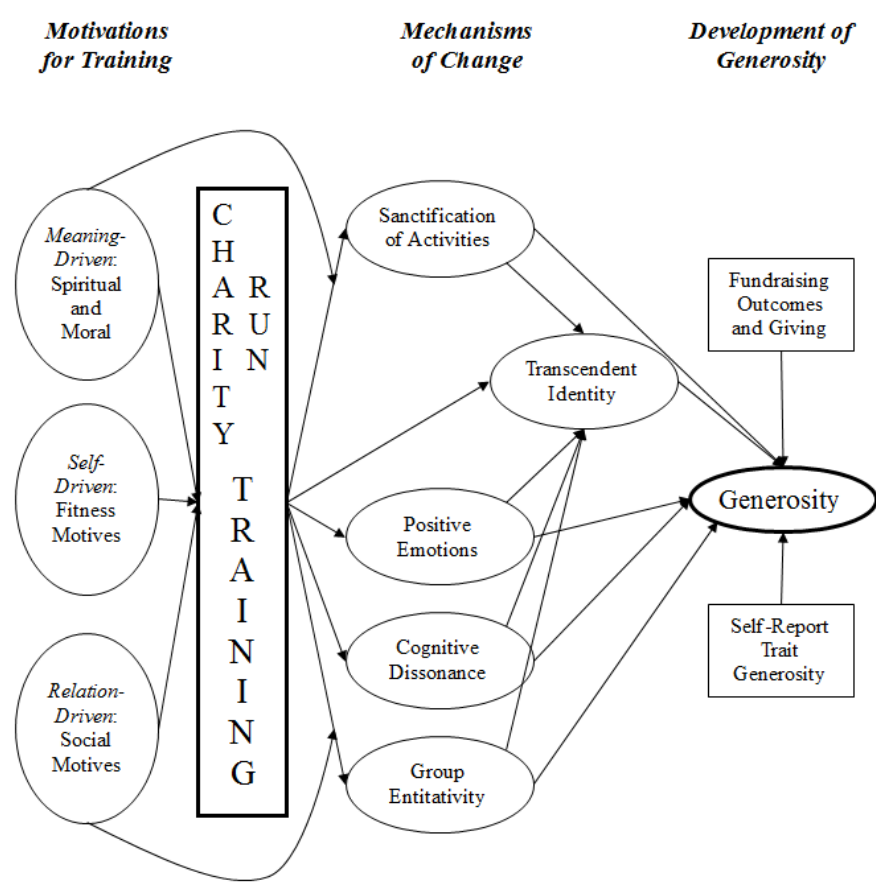

Figure 1. Theoretical model predicting generosity in the context of marathon participation.

\section{Theoretical Model}

\subsection{Predisposing Factors}

We begin with a discussion of those factors included in our model that predispose participants to join charity marathons. Charity sporting events have a broad appeal. Bennet, Mousley, Kitchin, and Ali-Choudhury examined the motivating factors for participation in charity sporting events and identified four major motivations: personal involvement with the good causes supported, opportunities to lead a healthy lifestyle, involvement in the sport in question, and a desire to mix socially with other attendees [16]. Out of these broad categories, adolescents may be particularly influenced by the opportunity that these events present to spend time socially with their peers, as peer influences are especially important in this developmental period [17]. Additionally, adolescents are typically more physically active than their adult counterparts [18], which makes the opportunity to stay physically fit and to participate in a marathon all the more appealing. This suggests that participants do not exclusively join such events out of a sense of moral duty to support the cause. Instead, youth participate in such activities for a broad variety of reasons. Youth who may not begin training for a charity run with explicit moral or spiritual motivations may still be afforded the opportunity to grow morally and spiritually as part of the experience. However, some youth do engage in running charity events primarily for the moral or transcendent purposes behind the event. Caprara, Alessandri, and Eisenberg showed that self-transcendent motivations in emerging adulthood are a predictor of engagement in prosocial behaviors, such as volunteering and charitable giving [19]. Specifically, they noted the presence of a value system that transcends the self-predicted empathic self-efficacy-the belief in an 
individual's ability to affect change for others and to help people beyond themselves. These findings suggest that self-transcendent motivation may be a key factor that enhances the positive impact of participating in charity sporting events and may lead to further participation.

In addition to these factors generally contributing to participation in charity marathons, there are religious and spiritual factors that may contribute to participation in charity events generally and religiously affiliated charity marathons in particular. Indeed, religion is often a primary context for self-transcendence in adolescents, and therefore, it is closely related to other forms of self-transcendence that are not specifically religious. In addition, religious persons are more likely to give of their time and energy to religiously affiliated groups [1]. Religious communities may foster a spirit of volunteerism and civic engagement. Caputo showed that parental religious affiliation significantly predicted youth volunteer behavior [20]. Beyerlein and Hipp showed that in some congregations religious participation resulted in increased civic engagement [21]. This seems to indicate that religious youth, especially those who are in religious communities modeling and promoting civic engagement, may have specifically religious motives to participate in charity marathons beyond the broadly social, moral, and fitness reasons which provide an incentive for all participants.

As can be seen in our model (Figure 1), all the motivations for engaging in active philanthropy are expected to contribute to adolescents' pursuing participation in charity marathons, and certain motivations are also expected to moderate the effects of the specific psychological processes activated by training. Moral and religious motivations for training are expected to moderate the effect of training on goal sanctification, such that those with higher religious and moral motivations will be more likely to sanctify the run, charitable goal, and fund-raising. Social motivations, meanwhile, are expected to moderate the effect of training on group entitativity (e.g., belongingness to and cohesiveness in the group) such that those with higher social motivation to participate will be more influenced by group processes inherent in the training. The rationale behind these proposed moderations will be explained presently in the discussion of each mechanism.

\subsection{Specific Mechanisms Active in Training}

These predisposing factors will increase adolescents' likelihood of becoming a participant in a charity sporting event, but how might that participation affect their generosity? And, more specifically, what are the particular mechanisms that will drive any change? As previously mentioned, a goal of our research is to better define the pathways that lead from participation in a charity marathon to a change in a person's generosity going forward. As seen in the figure, we propose that once adolescents join a charity marathon, whatever the predisposing reasons that are present, a series of psychological processes will be activated by their participation. We propose that these mechanisms will have unique effects upon participants, all leading to the eventual increase in generosity as shown. We have divided these mechanisms up into two groups: the "higher-order" spiritual and identity-based processes that may be particularly active in the context of charity sporting events and the "lower-order" mechanisms that are more universal social psychological processes.

\subsection{Higher-Order Mechanisms}

\subsubsection{Sanctification}

In this study, we are defining spirituality through the lens of sanctification. Sanctification is the psychological process by which people perceive or actively construe aspects of life as having a spiritual character or significance [22]. As previously mentioned, a variety of active philanthropy groups are religiously affiliated, and it is likely that many runners engage in charity runs and the like for religious and spiritual reasons. For individuals engaged in a training context with spiritual overtones, the process of sanctification may be a mechanism of change. Numerous studies have found that participants invest more effort into sanctified goals and derive greater satisfaction from achieving them. For instance, Pargament and Mahoney found that goal sanctification was positively 
correlated with effort invested, perceived support, and anticipation of success [22]. Additionally, Emmons, Cheung, and Tehrani found that participants with higher theistic strivings had higher goal instrumentality, which is a measure of how much the pursuit of one goal facilitates the pursuit of other goals in a person's goal system [23]. Even activities and goals that may not appear explicitly spiritual can be sanctified. For instance, people commonly imbue parenting or work with spiritual significance. In the case of training for a charity race, a person might find themselves sanctifying the charitable aim of the race and imbuing their fund-raising activity with the same spiritual significance.

Although sanctification is related to religiousness, it is a distinct psychological process. Pargament and Mahoney found that sanctification was correlated with church attendance and self-reported religiosity, but sanctification was uniquely associated with self-reports of meaning and purpose in life even after controlling for general religiousness [22]. Although we expect that participants in explicitly religious charities will sanctify their engagement, this research suggests it is possible that participants in non-religiously-affiliated charity work may also sanctify their participation, deriving meaning and purpose from their participation.

This sanctification of the charitable mission of the event would influence runners to view fund-raising goals as highly salient. Mahoney and colleagues showed that the more highly goals were sanctified, the more time and energy participants exerted on them on a daily basis. In the case of charity marathons, runners who sanctify the activity may exert increased time and effort expended on the charitable cause, which could then increase in generosity more broadly [24].

Team World Vision (TWV), the charity specifically investigated in our study, provides an example of how this mechanism would work in the real world. TWV is an arm of World Vision International specifically tasked with using charity running events to produce funds. A religious institution, World Vision describes itself as "a Christian humanitarian organization dedicated to working with children, families, and their communities worldwide to reach their full potential by tackling the causes of poverty and injustice... Motivated by our faith in Jesus Christ, we serve alongside the poor and oppressed as a demonstration of God's unconditional love for all people" [25]. Participants who take part in a marathon with TWV are inundated with this messaging. Through participation over months of training, it is likely that runners will be influenced by this message and may even come to share in this outlook to a lesser or greater extent. As some participants take on this worldview, they will likely begin to sanctify the process of fund-raising, which is hypothesized to increase effort expended pursuing this goal. This in turn is hypothesized to increase subsequent generosity not only in the context of TWV events but also in the broader context of charity programs that pursue similar aims. Further, as depicted in Figure 1, spiritual and religious motivations are likely to strengthen the positive relationship between engaging with TWV and goal sanctification. Thus, we expect that training with TWV will engage many young people to sanctify goals-whether or not they have initial spiritual motives. Of course, some runners may be completely immune to the spiritual message of the group, but most will be influenced by it to some extent. However, we would anticipate that the sanctification process would be stronger in young people who have a propensity to invest a spiritual or self-transcendent meaning in participation because these young people are already oriented toward spiritual meaning.

\subsubsection{Identity}

The second higher-order mechanism that we include in our model is identity development. As noted above, part of the way sanctification seems to affect goal achievement is through its relationship to increased meaning and purpose in life, or in other words, a meaningful identity. Identity development is a primary developmental task of adolescence [26], and identity has been linked to volunteering and prosocial behavior. For instance, Crocetti, Erentaite, and Žukauskienè showed that varying identity styles were related to frequency of volunteering [27]. Similarly, Furrow, King, and White showed that personal meaning was related to prosocial personality, and spiritual identity was also related to these constructs [28]. 
McAdams and Pals argue for three levels of personality, including basic tendencies or traits, contextualized middle-level units called characteristic adaptations, and personal identity narratives [29]. McCrae and Costa argue for a similar three-level system, though using different terminology [30]. Narrative identity specifically is conceptualized by McAdams and Pals as the dynamic life story that an individual uses to make sense of the particular series of events that occur in one's life [29]. Bauer, McAdams, and Pals argue that narrative identity is tied to eudaimonic well-being outcomes [31]. Eudaimonia, a word borrowed from the tradition of Aristotelian ethics, refers to the cultivation of the objectively good life and the highest expression of character and virtue. Within this framework, the development of generosity is an aspect of eudaimonic well-being because it is connected to meaningful personal growth and the cultivation of character strengths.

Bauer, McAdams, and Pals assert that the process of constructing a narrative identity involves fitting the seemingly random series of events in one's life into a coherent narrative by drawing on themes, symbols, plot devices, and so forth which are typically gleaned from the cultural context [31]. Narratives that interpret life events into the overall frameworks of growth stories are associated with greater well-being, especially eudaimonic well-being. Indeed, McAdams showed that participants who scored high on generativity measures had redemptive narrative identities that drew heavily on their participation in religious communities, spiritual activities, and civic engagement [32]. The study demonstrates that when people situate their narrative identity within the framework of a system that transcends self-goals, they experience greater eudaimonic well-being and virtue development. This likely occurs because transcending self-goals taps in to community ideals and narrative tropes of purpose in life. As participants engage in charity marathons with self-transcendent missions — especially religiously affiliated charities that emphasize transcendent meaning — they may be more likely to construct narrative identities that promote the development of generosity.

Referring again to TWV as a concrete example, the self-transcendent religious narratives of TWV can serve as a rich cultural resource for participants and can provide narrative frameworks and devices through which TWV runners can view the events in their life in terms of a growth narrative. As participants incorporate these self-transcendent narratives into their own identities, it is likely that they will develop a firmer sense of self and an identity that increases eudaimonic well-being. Prosocial engagement and character, including generosity, are likely to be a major part of the narrative identities that the participants construct, and their inclusion as central components of identity are hypothesized to engender more generous giving of time and money. As participants then act out this new identity in fundraising and running for charity, the incorporation of generosity into identity may become solidified.

\subsection{Lower-Order Mechanisms}

As mentioned, both increased sanctification and increased identity development are higher-order factors that are activated by participation in charity marathons. A number of other mechanisms are also included in our model. These mechanisms are more basic psychological processes, but nonetheless, they are hypothesized to serve as key pathways by which marathon training may increase generosity. These lower-order mechanisms include increased entitativity, cognitive dissonance, and increased positive emotion.

\subsubsection{Increased Entitativity}

The first lower-order mechanism presented in the model is increased group entitativity. Entitativity is a sense of belongingness to a group and perceiving that group as a single cohesive entity [33]. In a group with high entitativity, members feel like they are highly connected to each other and to the goals of the group; whereas in a group with low entitativity, members feel less connected and more individual. The intensive group training in which participants engage during preparation to run a marathon affords them the opportunity to form strong in-group bonds. Additionally, team leaders have the opportunity to exert additional influence on participants; previous research shows that 
coach leadership and relationship variables contribute to increased group cohesion [34]. This increase in group belongingness is likely to have the effect of increasing subsequent generosity. Bernhard, Fischbacher, and Fehr suggest that there is a basic human tendency towards parochial altruism-or giving to one's own social group—on the basis of anthropological research [35]. For instance, members of university groups that promote strong in-group ties, such as fraternities, sororities, and athletic teams, are more likely to give to their universities after graduation [36,37]. Thus, people with strong group ties are more willing to give to what is considered central to the group's identity.

The increased group cohesion may play an additional role beyond the simple promotion of belongingness. Research has shown that there is a tendency for people in a group to adapt their giving practices to be more similar to those of others in their group [38]. Those participants who are drawn to participate in a charity run event for religious or moral reasons likely already participate in charitable giving at a higher rate than their peers. Additionally, the team captains and program employees participating alongside new runners are likely to be exemplars of charitable giving and intentionally fostering group norms of generosity. Thus, it is hypothesized that a group effect will emerge by which the group exerts pressure on those who are participating in the event to be generous. For those who started out less generous, the positive group norm should influence them to become more generous.

Moreover, strong moral norms in combination with high group cohesion present the possibility that behaviors are undertaken in order to increase reputation within the group. This is the main principle behind costly signaling theory, which maintains that a person might be motivated to undertake a costly behavior (such as participating in a marathon or raising a large amount of money for a charitable cause) in order to signal they were sincerely committed to a group. A recent study on costly signaling theory of religion used the innovative method of examining the longevity of religious communes as a function of the costliness of their membership [39]. They found that groups with more stringent entry requirements lasted longer than more permissive groups because groups with higher entry costs typically promote a greater feeling of belongingness and commitment to the group. In the context of charity marathons, those participants who want to demonstrate their commitment to the group for social approval are incentivized to engage in generous acts of fund-raising, which leads to higher levels of generosity. Although generosity due to group belongingness factors may initially increase because of external motivations, it is hypothesized that over time the group norms become internalized through cognitive dissonance processes (see below) and as the group's identity becomes central to the self. Thus, entitativity will not only change generous behavior within the race team context, but it will also change generosity outside the context to the extent that group norms are internalized by the individual.

Referring back to our model and case example, TWV marathon runners will experience this increased group entitativity as they engage in the grueling process of training for a marathon. The high level of camaraderie will be a positive experience for most participants, and they will come to identify strongly with the group. As participants identify strongly with their TWV teams, they will be motivated to become more generous in giving to TWV. This increase in giving will be primarily driven by loyalty to the group, peer influence, and the desire to earn social standing through generous acts. These influences will help participants to develop generous habits, which may internalize over time. As shown in the diagram, these group processes should be particularly influential for those participants choosing to engage in the marathon for social reasons, as they will be more invested in group belongingness and social connections the training provides.

\subsubsection{Positive Emotionality in Marathon Participation}

The next lower-order mechanism is positive emotionality. Participating in charity marathons is an enjoyable activity for many, which is likely why charity sporting events are so popular. How might an increase in positive emotionality experienced from participating in a charity run relate to increased generosity? According to the broaden-and-build theory of positive emotions, positive emotions increase peoples' behavioral repertoires and expand their openness to new possibilities in 
the environment, which they are likely to explore [40]. In essence, positive emotions open people up to take risks and form new experiences. This then would likely increase subsequent generosity as participants in a good mood spread that good mood through generosity. Previous studies have supported this premise, demonstrating that inducing positive emotions like gratitude can increase giving in the laboratory [41].

A variety of factors are likely to underlie the enjoyability of charity marathon participation. In part, marathon training, though difficult, is enjoyable because of the effects of physical activity on positive emotions. Fox showed physical activity was such a reliable means to increase positive emotions and regulate negative emotions that he suggested it should be considered a viable treatment for depression and anxiety [42]. In a review of physical activity research, Penedo and Dahn highlighted the positive effects of physical activity on a variety of mood outcomes in addition to the physical health benefits it conveyed [43].

Beyond the positive effects of physical activation, participating in charity marathons also has higher-order psychological effects that are linked to increased positive affect. The goal sanctification that charity marathons engender has been associated with positive emotional outcomes. Tix and Frazier found that goal sanctification was associated with decreased anxiety, hostility, and depression [44]. Similarly, Pargament and Mahoney found that participants derived a greater degree of meaning and life satisfaction from sanctified goals compared to self or materially oriented goals [22]. In general, the pursuit of sanctified goals leads to better emotional outcomes for all involved.

In addition to these benefits there are many emotional benefits associated with giving itself. Thotis showed that volunteering was associated with greater meaning and purpose in life, which in turn was related to greater well-being [45]. Hallam and colleagues found that adolescents who participated in activities meant to benefit others demonstrated greater emotional competence in young adulthood, and this emotional competence reduced the risk of developing adult anxiety and depression [46]. Aknin et al., presented a series of studies suggesting that the positive experience of giving to others is a cultural universal [47], and imaging studies provide evidence that giving behaviors produced similar brain activation as receiving a reward [48].

With these factors and perhaps others contributing to the enjoyability of charity sporting event participation, runners' positive emotions will likely be strongly elevated by their participation in the charity activities. Referring back to the broaden-and-build theory, this increase in positive emotionality will predict a subsequent increase in prosocial behaviors as participants broaden their social networks and build upon their experience. What is more, there is evidence that an upward, "virtuous" cycle whereby giving produces happiness, which produces greater giving, and so forth can be activated [49].

In applying our model to the case study of training for TWV marathons, participants join for a variety of reasons and goals for their training experience. The experience likely fulfills these desires (i.e., providing an opportunity for participants to demonstrate their religious and moral convictions, providing physical activity outlets, and providing social interaction with peers), which likely increases positive emotions. The benefits of training described above are also likely to then induce positive emotions, which prompt them to give more generously of their time and money.

\subsubsection{Dissonance Reduction}

A final major contributing factor to the effects of participating in charity sporting events on change in generosity is the process of value system change facilitated though dissonance reduction. The idea of attitude change through cognitive dissonance (the mental stress associated with a contradiction between belief/attitudes and behavior) has been a vital part of social psychology since the theory was proposed [50]. The theory maintains that when people experience dissonance, they will change either their beliefs/attitudes or their behaviors to bring the two into alignment.

It is likely that a large number of people participating in charity marathons do not sanctify the goals of the charity or situate their narrative identities within a self-transcendent framework. As previously stated, many participants are joining marathons for social, health, and sporting reasons 
rather than moral or spiritual reasons. However, participating in a marathon is a huge commitment. According to Running USA, only 541,000 people finished a marathon in 2014 [51], and newspapers such as the Huffington Post have published satirical articles highlighting reasons not to run marathons [52]. All participants training for a marathon will experiences difficulties and challenges in training. Though training leads to positive emotions, it also involves hardships and a large amount of effort. This means that participants who train for more self-focused reasons will likely feel dissonance as they expend a high degree of energy to train for an event supporting a charity for which they may not have that much investment.

In order to alleviate this dissonance, participants will either need to alter their behavior or their attitudes. Thus, participants who feel dissonance but who choose to persist in running the marathon will naturally increase their commitment to the charitable cause promoted by the organization (i.e., changing their attitudes to align with their behavior). Increased fund-raising and generosity would then follow this increased commitment to avoid additional dissonance. The increased commitment may also lead to a sanctification of the goals of the charity and to using these goals as an organizer of the participants' personality, the two higher-order mechanisms we previously discussed. In turn, this increase in sanctification and identity development could lead to increased generosity, as previously outlined. Research on disaster responses to the 2004 Red Cross tsunami relief supports this supposition; it found that people are more likely to contribute to causes when they felt dissonance, and that the contributions helped to restore psychological equilibrium [53].

In the case of TWV, marathon participants join the marathon for a variety of reasons. Regardless of why they joined, however, they spend 18 weeks training for an intense 26.2-mile race, which is grueling both mentally and physically. This is hypothesized to create a high amount of dissonance for those who do not initially believe in the cause or value generosity, as a discrepancy will likely arise between their attitudes and behaviors. Participants making costly signals of group membership by being particularly generous may experience dissonance if they find themselves giving heavily of time and money to a cause for which they do not have initially high levels of commitment. Participants may continue to train because they like the positive emotions it brings or the group entitativity experience, but they may also need to justify their actions rationally in order to reduce dissonance. For some participants, this may lead them to modify their value system in order to reduce dissonance. In order to do this, they will likely incorporate the sanctified pursuit of the clean water initiatives supported by TWV into their own motivational frameworks and use the self-transcendent mission of the TWV project as an organizing tool for their personalities. Thus, they may become more generous people as they adopt the prosocial agenda of TWV.

\section{Discussion}

\subsection{Summary}

In summary, we have proposed a model for understanding the role of various psycho-spiritual processes in explaining how adolescents' participation in charity sporting events fosters generosity. Adolescents are motivated by a variety of social, physical, and religious/moral reasons to participate in charity sporting events. These events may or may not be religiously affiliated, but they are all inherently self-transcendent in their focus on charitable giving to others. Charity sporting events are theorized to serve as a developmental asset for building generosity through at least five interrelated higherand lower-order mechanisms. First, charity organizers promote the sanctification of the charitable cause, which increases participants' drive to accomplish self-transcendent goals, which may increase their generosity. Second, organizers also provide a self-transcendent identity context for participants. Participants are able to view their identity and purpose in life as being tied to something greater than themselves, which increases eudaimonic well-being, including generosity. The conditions of these particular types of events further promote generosity beyond these mechanisms through a series of lower-order mechanisms. Namely, increased group entitativity motivates adolescents to conform their 
ideals and generous behaviors to the norm of the group, which is likely more self-transcendent and generosity-promoting than a typical sample of nonparticipants. Additionally, participation in training has the capacity to produce a variety of positive emotions, which may increase the likelihood of future generosity as participants broaden and build their experience; ultimately, this may trigger a virtuous cycle of positive emotion and generosity. Lastly, participants are placed in high-demand situations that require a great deal of effort expenditure, promoting a dissonance reaction that may be resolved by an increased commitment to generosity.

\subsection{Methodological Challenges}

There are a variety of methodological challenges inherent in a project such as this. First, measurement of generosity, the key outcome, is complicated in adolescents. Adolescents typically have few financial resources to contribute to an organization despite their desires to give, so dependence upon actual giving is problematic in assessment. Moreover, measuring generosity in terms of financial resources contributed to charitable causes is confounded by socioeconomic status. However, relying on other indicators of generosity has challenges because questionnaire data has inherent self-report bias and measuring volunteer time committed is difficult in this context because all participants are dedicating a majority of their free time to the training for the marathon itself. Therefore, multiple generosity indicators are needed to try to gain a complete picture of the phenomenon as it occurs in this and other real-world contexts. In the study we conduct, we assess both self-reported change in generosity as well as fund-raising outcomes (quantified as both total dollars raised and number of donors). We encourage research teams to employ multiple measures of generosity that capture behaviors in addition to self-assessments.

Measurement issues also exist in assessing what motivates participants to engage in charity marathon training because this is not a very often studied area. Similarly, the measurement of spirituality and religiosity is always challenging, but it is especially so in adolescent populations where there is a high degree of volatility in identity and belief systems. However, it is this very developmental plasticity that makes studying the development of generosity in this context so fruitful. In order to account for these difficulties, we propose that researchers adopt a mixed method design. For example, in the TWV case study we describe, we combine observable behavioral data with quantitative self-reports and semi-structured qualitative interviews in order to try to develop a more ecologically valid picture of these processes as they unfold.

Finally, testing the model we propose requires longitudinal assessment. It is essential to measure motives for training before training begins, the mechanisms of change during the training, and generosity after the race is complete. Moreover, several of the mechanisms proposed imply that the race experience would lead to changes in identity and generosity that last beyond the training experience. Thus, a post-race follow-up several months after the event is finished allows for a full test of the model.

\section{Conclusions}

This proposed theoretical model and suggestions for research design are important because they aim to address gaps in areas of existing research related to the development of adolescent spirituality, religiousness, and generosity. We propose a study protocol that uses a rich mixed method design to assess adolescent experiences of religious charity marathon participation by utilizing multiple sources of information including surveys, interviews, and fund-raising. We hope others will follow our example by employing designs that ensure ecological validity by studying the development of generosity and religiosity in context and observing the developmental processes at work through activities in which adolescents are already participating. Although laboratory studies are valuable, we strongly encourage researchers to also engage in studies with such generalizability. However, just because research takes place in the field does not mean researchers should desist in examining specific mechanisms of change. In our proposed theory and case study, we aim to test specific mechanisms that 
may explain the link between religiosity and generosity rather than studying the link more broadly with less depth.

As this research is ongoing, the theoretical model described is yet untested. However, we hope that it can serve as a stimulus for other researchers who might be interested in this topic to consider investigating this relatively under-studied area and to continue to develop a knowledge base for understanding how religious charity sporting events and other transformational contexts may impact adolescent positive development.

Acknowledgments: This publication was made possible through the support of a grant from the John Templeton Foundation. The opinions expressed in this publication are those of the authors and do not necessarily reflect the views of the John Templeton Foundation.

Author Contributions: Nathaniel Fernandez (N.F.), Sarah Schnitker (S.S.), and Benjamin Houltberg (B.H.) were all involved in the conceptual development of the theoretical model. Nathaniel Fernandez wrote the first draft of the paper. Sarah Schnitker wrote extensive revisions of the paper. Benjamin Houltberg made additional modifications to the manuscript. Sarah Schnitker procured the grant supporting this work and originally designed the TWV case study described. Benjamin Houltberg oversees the execution of the TWV case study and its ongoing revision.

Conflicts of Interest: The authors declare no conflict of interest.

\section{References}

1. Bekkers, René, and Pamala Wiepking. "Who gives? A literature review of predictors of charitable giving part one: Religion, education, age and socialization." Voluntary Sector Review 2 (2011): 337-65. [CrossRef]

2. Galen, Luke W. "Does religious belief promote prosociality? A critical examination." Psychological Bulletin 138 (2012): 876-906. [CrossRef] [PubMed]

3. Lenhart, Amanda, Kristen Purcell, Aaron Smith, and Kathryn Zickuhr. Social Media \& Mobile Internet Use among Teens and Young Adults. Millennials. Washington: Pew Internet \& American Life Project, 2010.

4. Smith, Christian, and Jonathan P. Hill. "Toward the measurement of Interpersonal Generosity (IG): An IG scale conceptualized, tested, and validated." 2009. Available online: https://generosityresearch.nd.edu/ assets/13798/ig_paper_smith_hill_rev.pdf (accessed on 21 January 2016).

5. Davis, Mark H. "Measuring individual difference in empathy: Evidence for a multidimensional approach." Journal of Personality and Social Psychology 44 (1983): 113-26. [CrossRef]

6. Benson, Peter L. "Emerging themes in research on adolescent spiritual and religious development." Applied Developmental Science 8 (2004): 47-50. [CrossRef]

7. Büssing, Arndt, Axel Föller-Mancini, Jennifer Gidley, and Peter Heusser. "Aspects of spirituality in adolescents." International Journal of Children's Spirituality 15 (2010): 25-44. [CrossRef]

8. Warren, Alberts, Amy Eva, Richard M. Lerner, and Erin Phelps, eds. Thriving and Spirituality among Youth: Research Perspectives and Future Possibilities. Hoboken: John Wiley \& Sons, 2012.

9. James, Anthony G., and Mark A. Fine. "Relations between youths' conceptions of spirituality and their developmental outcomes." Journal of Adolescence 43 (2015): 171-80. [CrossRef] [PubMed]

10. Spiewak, Gabriel S., and Lonnie R. Sherrod. "The shared pathways of religious/spiritual engagement and positive youth development." In Thriving and Spirituality among Youth: Research Perspectives and Future Possibilities. Edited by Amy Eva Alberts Warren, Richard M. Lerner and Erin Phelps. Hoboken: John Wiley \& Sons, 2012, pp. 167-81.

11. Büssing, Arndt, Philipp Kerksieck, Andreas Günther, and Klaus Baumann. "Altruism in adolescents and young adults: Validation of an instrument to measure generative altruism with structural equation modeling." International Journal of Children's Spirituality 18 (2013): 335-50. [CrossRef]

12. Shariff, Azim F., and Ara Norenzayan. "God is watching you: Priming God concepts increases prosocial behavior in an anonymous economic game." Psychological Science 18 (2007): 803-9. [CrossRef] [PubMed]

13. Desrosiers, Alethea, Brien S. Kelley, and Lisa Miller. "Parent and peer relationships and relational spirituality in adolescents and young adults." Psychology of Religion and Spirituality 3 (2011): 39-54. [CrossRef]

14. Feldman, Naomi E. "Time is money: Choosing between charitable activities." American Economic Journal: Economic Policy 2 (2010): 103-30. [CrossRef]

15. Benson, Peter L., Peter C. Scales, Stephen F. Hamilton, and Arturo Sesma. Positive Youth Development: Theory, Research, and Applications. Hoboken: John Wiley \& Sons, 2006. 
16. Bennett, Roger, Wendy Mousley, Paul James Kitchin, and Rehnuma Ali-Choudhury. "Motivations for participating in charity-affiliated sporting events." Journal of Customer Behavior 6 (2007): 155-78. [CrossRef]

17. Gardner, Margo, and Laurence Steinberg. "Peer influence on risk taking, risk preference, and risky decision making in adolescence and adulthood: An experimental study." Developmental Psychology 41 (2005): 625-35. [CrossRef] [PubMed]

18. Caspersen, Carl J., Mark A. Pereira, and Katy M. Curran. "Changes in physical activity patterns in the United States, by sex and cross-sectional age." Medicine and Science in Sports Exercise 32 (2000): 1601-9. [CrossRef]

19. Caprara, Gian V., Guido Alessandri, and Nancy Eisenberg. "Prosociality: The contribution of traits, values, and self-efficacy beliefs." Journal of Personality and Social Psychology 102 (2012): 1289-303. [CrossRef] [PubMed]

20. Caputo, Richard K. "Religious capital and intergenerational transmission of volunteering as correlates of civic engagement." Nonprofit and Voluntary Sector Quarterly 38 (2009): 983-1002. [CrossRef]

21. Beyerlein, Kraig, and John R. Hipp. "From pews to participation: The effect of congregation activity and context on bridging civic engagement." Social Problems 53 (2006): 97-117. [CrossRef]

22. Pargament, Kenneth I., and Annette M. Mahoney. "Sacred matters: Sanctification as a vital topic for the psychology of religion." The International Journal for the Psychology of Religion 15 (2005): 179-262. [CrossRef]

23. Emmons, Robert A., Chi Cheung, and Keivan Tehrani. "Assessing spirituality through personal goals: Implications for research on religion and subjective well-being." Social Indicators Research 45 (1998): 391-422. [CrossRef]

24. Mahoney, Annette, Kenneth I. Pargament, Brenda Cole, Tracey Jewell, Gina M. Magyar, Nalini Tarakeshwar, and Russell Phillips. "A higher purpose: The sanctification of strivings in a community sample." The International Journal for the Psychology of Religion 15 (2005): 239-62. [CrossRef]

25. World Vision. "Who We Are." 2015. Available online: http://www.worldvision.org/about-us/who-we-are (accessed on 21 January 2016).

26. Erikson, Erik H. Identity: Youth and Crisis. New York: WW Norton, 1968.

27. Crocetti, Elisabetta, Rasa Erentaitè, and Rita Žukauskienè. "Identity styles, positive youth development, and civic engagement in adolescence." Journal of Youth and Adolescence 43 (2014): 1818-28. [CrossRef] [PubMed]

28. Furrow, James L., Pamela E. King, and Krystal White. "Religion and positive youth development: Identity, meaning, and prosocial concerns." Applied Developmental Science 8 (2004): 17-26. [CrossRef]

29. McAdams, Dan P., and Jennifer Lilgendahl Pals. "A new big five: Fundamental principles for an integrative science of personality." American Psychologist 61 (2006): 208-17. [CrossRef] [PubMed]

30. McCrae, Robert R., and Paul T. Costa. "The five-factor theory of personality." In Handbook of Personality: Theory and Research. Edited by Oliver P. John, Richard W. Robins and Lawrence A. Pervin. New York: Guilford, 2008, pp. 159-81.

31. Bauer, Jack J., Dan P. McAdams, and Jennifer L. Pals. "Narrative identity and eudaimonic well-being." Journal of Happiness Studies 9 (2008): 81-104. [CrossRef]

32. McAdams, Dan P. “Generativity in midlife." In Handbook of Midlife Development. Edited by Margie E. Lachman. New York: Wiley, 2001, pp. 395-443.

33. Lickel, Brian, David L. Hamilton, Grazyna Wieczorkowska, Amy Lewis, Steven J. Sherman, and A. Neville Uhles. "Varieties of groups and the perception of group entitativity." Journal of Personality and Social Psychology 78 (2000): 223-46. [CrossRef] [PubMed]

34. Jowett, Sophia, and Victoria Chaundy. "An investigation into the impact of coach leadership and coach-athlete relationship on group cohesion." Group Dynamics, Theory, Research, and Practice 8 (2004): 302-14. [CrossRef]

35. Bernhard, Helen, Urs Fischbacher, and Ernst Fehr. "Parochial altruism in humans." Nature 442 (2006): 912-15. [CrossRef] [PubMed]

36. Harrison, William B., Shannon K. Mitchell, and Steven P. Peterson. “Alumni donations and colleges' development expenditures: Does spending matter? " The American Journal of Economics and Sociology 54 (1995): 397-413. [CrossRef]

37. Marr, Kelly A., Charles H. Mullin, and John J. Siegfried. “Undergraduate financial aid and subsequent alumni giving behavior." The Quarterly Review of Economics and Finance 45 (2005): 123-43. [CrossRef]

38. Wu, Shih-Ying, Jr-Tsung Huang, and An-Pang Kao. "An analysis of the peer effects in charitable giving: The case of Taiwan." Journal of Family and Economic Issues 25 (2004): 483-505. [CrossRef] 
39. Sosis, Richard, and Eric R. Bressler. "Cooperation and commune longevity: A test of the costly signaling theory of religion." Cross-Cultural Research 37 (2003): 211-39. [CrossRef]

40. Fredrickson, Barbara L. "The role of positive emotions in positive psychology: The broaden-and-build theory of positive emotions." American Psychologist 56 (2001): 218-26. [CrossRef] [PubMed]

41. DeSteno, David, Monica Y. Bartlett, Jolie Baumann, Lisa A. Williams, and Leah Dickens. “Gratitude as moral sentiment: Emotion-guided cooperation in economic exchange." Emotion 10 (2010): 289-93. [CrossRef] [PubMed]

42. Fox, Kenneth R. “The influence of physical activity on mental well-being." Public Health Nutrition 2 (1999): 411-18. [CrossRef] [PubMed]

43. Penedo, Frank J., and Jason R. Dahn. "Exercise and well-being: A review of mental and physical health benefits associated with physical activity." Current Opinion in Psychiatry 18 (2005): 189-93. [CrossRef] [PubMed]

44. Tix, Andrew P., and Patricia A. Frazier. "Mediation and moderation of the relationship between intrinsic religiousness and mental health." Personality and Social Psychology Bulletin 31 (2005): 295-306. [CrossRef] [PubMed]

45. Thotis, Peggy A. "Role-identity salience, purpose and meaning in life, and well-being among volunteers." Social Psychology Quarterly 75 (2012): 360-84. [CrossRef]

46. Hallam, William T., Craig A. Olsson, Meredith O'Connor, Mary Hawkins, John W. Toumbourou, Glenn Bowes, Rob McGee, and Ann Sanson. "Association between adolescent eudaimonic behaviours and emotional competence in young adulthood." Journal of Happiness Studies 15 (2014): 1165-77. [CrossRef]

47. Aknin, Laura B., Christopher P. Barrington-Leigh, Elizabeth W. Dunn, John F. Helliwell, Justine Burns, Robert Biswas-Diener, Imelda Kemeza, Paul Nyende, and Michael I. Norton. "Prosocial spending and well-being: Cross-cultural evidence for a psychological universal." Journal of Personality and Social Psychology 104 (2015): 635-52. [CrossRef] [PubMed]

48. Harbaugh, William T., Ulrich Mayr, and Daniel R. Burghart. "Neural responses to taxation and voluntary giving reveal motives for charitable donations." Science 316 (2007): 1622-24. [CrossRef] [PubMed]

49. Aknin, Laura B., Elizabeth W. Dunn, and Michael I. Norton. "Happiness runs in a circular motion: Evidence for a positive feedback loop between prosocial spending and happiness." Journal of Happiness Studies 13 (2012): 347-55. [CrossRef]

50. Festinger, Leon. A Theory of Cognitive Dissonance. Palo AltoStanford: Stanford University Press, 1957.

51. Running USA. “2014 Annual Marathon Report.” 2014. Available online: http://www.runningusa.org/index. cfm?fuseaction=news.details\&ArticleId=332 (accessed on 21 January 2016).

52. Klein, Sarah. "26 Reasons not to Run a Marathon.” The Huffington Post, 2013. Available online: http:/ / www. huffingtonpost.com/2013/10/29/why-not-shouldnt-run-marathon_n_4171186.html (accessed on 21 January 2016).

53. Waters, Richard D. "Examining the role of cognitive dissonance in crisis fundraising." Public Relations Review 35 (2009): 139-43. [CrossRef]

(C) 2016 by the authors; licensee MDPI, Basel, Switzerland. This article is an open access article distributed under the terms and conditions of the Creative Commons by Attribution (CC-BY) license (http://creativecommons.org/licenses/by/4.0/). 